\title{
Alternative method of outside-in meniscal repair for anterior horn tears
}

\section{Pedro Manuel Serrano Tiago Amorim-Barbosa Marta Santos Silva Ricardo Sousa}

Centro Hospitalar do Porto Orthopedic Department, Centro Hospitalar do Porto, Porto, Portugal

Correspondence: Pedro Manuel Serrano Serviço de Ortopedia e Traumatologia, Centro Hospitalar do Porto, Hospital de Santo António, Largo Professor Abel Salazar, 4099-00I Porto, Portugal Email pms1983@gmail.com
This article was published in the following Dove Press journal: Open Access Journal of Sports Medicine

\begin{abstract}
Treatment of symptomatic meniscal tears continues to evolve as we improve our understanding of the biomechanical role of the meniscus and its long-term importance to the health of the knee joint. Suture repair of meniscal tears is challenging and continues to rise as we aim to preserve meniscal tissue. Outside-in meniscal suture techniques may involve using expensive equipment that is not readily available for immediate use in most operating rooms. Aware of the different techniques available, the authors describe a fast and reproducible technique that does not require the use of specific material or equipment.
\end{abstract}

Keywords: meniscal suture, arthroscopy, sports trauma, surgical technique

\section{Introduction}

Arthroscopic meniscal repair was first introduced by Ikeuchi in Tokyo in 1979. ${ }^{1}$ Whenever a repairable meniscal rupture is detected, arthroscopic suturing is currently the procedure of choice. Indications for meniscal suture include complete vertical longitudinal ruptures (over $10 \mathrm{~mm}$ ), peripheral ruptures (included in the most peripheral third), or those within 3 or $4 \mathrm{~mm}$ of the meniscocapsular junction. ${ }^{2}$ Arthroscopic repair techniques can be categorized into 4 groups: inside-out, outside-in, all-inside (entirely intra-articular), and hybrid. None of these techniques is considered as the gold standard for all situations. The outside-in technique, described by Morgan and Casscells, is best indicated for ruptures of the middle or anterior meniscal third and avoids the occasional neurovascular complications of the inside-out techniques. ${ }^{3}$ The all-inside technique is especially useful in posterior horn ruptures, and due to the narrow articular space, it can be technically difficult to perform. The development of devices for suture passage has made the technique progressively easier, with the advantage of not requiring additional skin incisions. On the other hand, the cost of these devices and the technical difficulties when they are not available (eg, when lesions were not previously diagnosed) are disadvantages. Both outside-in and inside-out techniques inevitably result in an additional incision, even larger if the repair is in the posterior horn, to provide good visualization of structures to avoid. ${ }^{4}$ Given that outside-in meniscal suture may involve the use of expensive materials, the authors describe a simple, effective, and reproducible technique using inexpensive materials, widely available in operating rooms.

\section{Technique}

Systematic arthroscopic examination is performed through conventional anterior arthroscopic portals using a $30^{\circ}$ arthroscope. The meniscal lesion is carefully examined 
to determine its location, extent, and stability. After confirming that it is a reparable lesion, the surgeon passes a needle through the skin, capsule, and meniscus, to reach the desired site for meniscal repair. We recommend the use of a smaller needle at this early stage, especially for less-experienced surgeons, to avoid unnecessary tissue damage that may be caused by excessive passages. After identifying the optimal site for needle insertion, a $10 \mathrm{~mm}$ transverse cutaneous incision is made at this site. Only one 16-gauge needle previously prepared with Ethibond ${ }^{\circledR} 2$ suture (Ethicon, Somerville, NJ, USA) is used. The needle with the preassembled thread is then placed along the path of the previously inserted needle, which has since been removed (Figure 1). The needle should then be withdrawn (outside the joint), leaving the thread inside in the chosen location. When this needle is pulled back, one part of the thread remains inside the needle and the other inside the joint. The same needle (that still carries the suture thread) should be inserted again (through the same incision) and, with this step, a loop is created (Figure 2). In the same way, the needle is removed, avoiding simultaneous exit of the previously introduced loop. A grasp is passed through the most appropriate arthroscopic portal to gain access to the sutures. It goes through the loop and grasps the suture inserted in step 1 (Figure 3). With the initial thread already passing through the loop, the surgeon pulls the loop out (using the correspondent extra-articular thread), exteriorizing the tip of the thread introduced in step 1 (Figure 4). Using both ends of the same thread, it is possible to test the stability of the
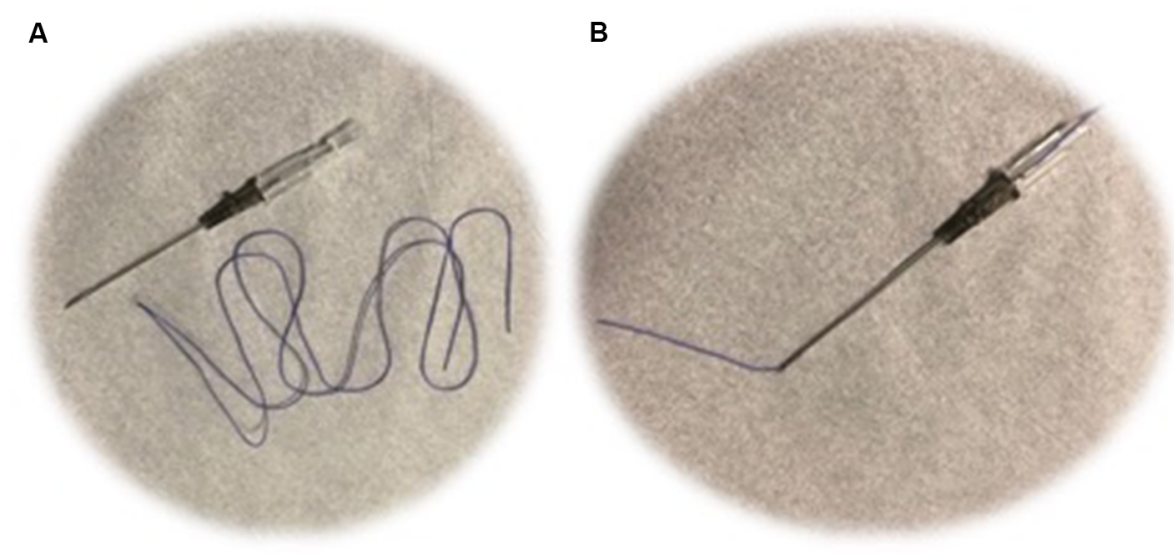

Figure I (A) Required material. (B) One I6-gauge needle prepared with ethibond suture.
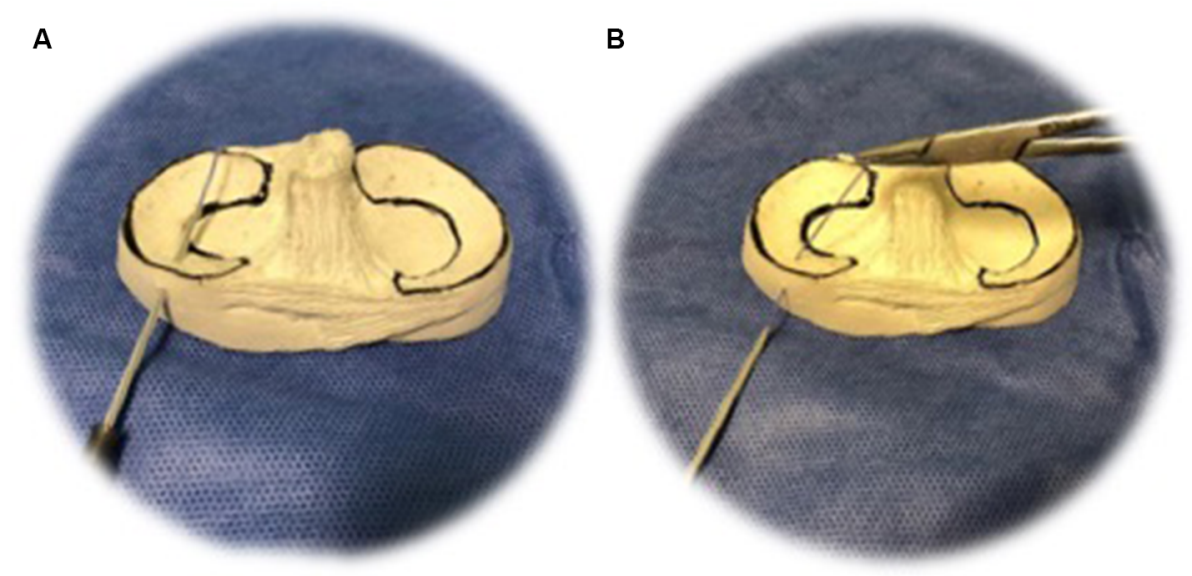

Figure 2 The needle with the preassembled thread is placed through the desired site for meniscal repair (A). The needle should then be withdrawn to the outside, causing the thread to remain inside at the same place in meniscus (B). It is important to understand that when this needle is pulled back, one part of the thread remains inside the needle and the other inside the joint. 

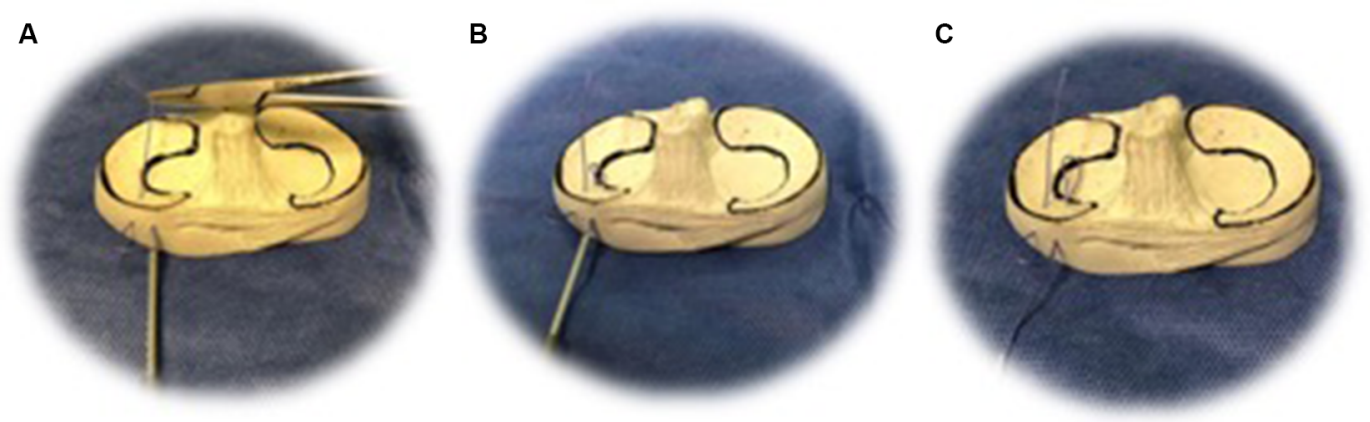

Figure 3 The same needle should be inserted again (without removing the suture thread that always remained inside the needle; $\mathbf{A}$ ), creating a loop. In the same way (B), the needle should be removed (outside of the joint; $\mathbf{C}$ ), avoiding the simultaneous exit of the previously introduced loop.
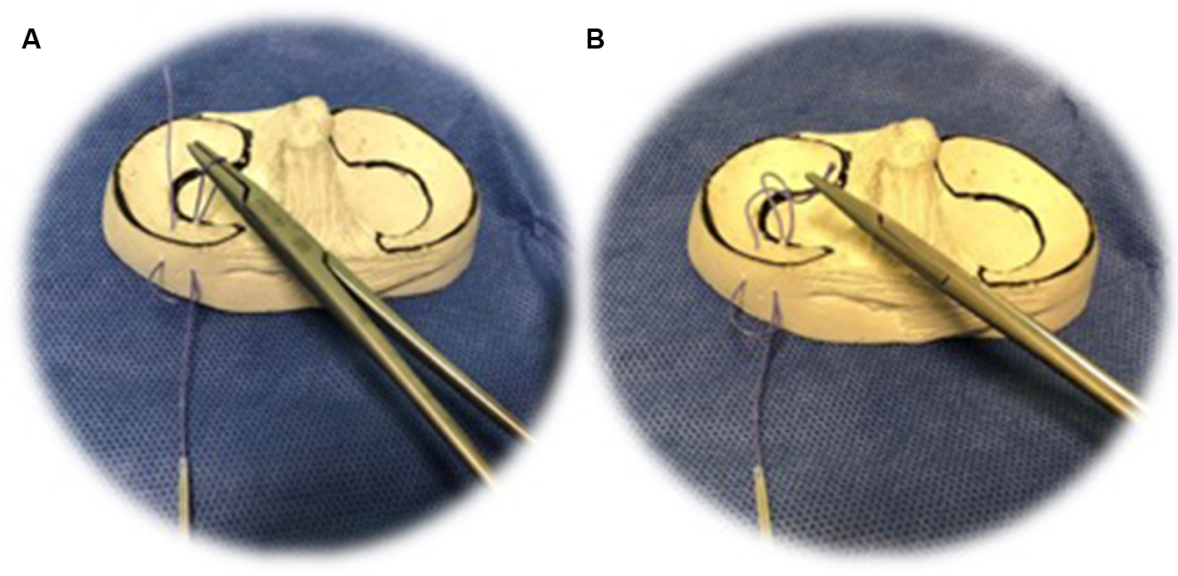

Figure $4 \mathrm{~A}$ grasp is passed through the loop $(\mathbf{A})$ and grasps the suture inserted in step I (B).
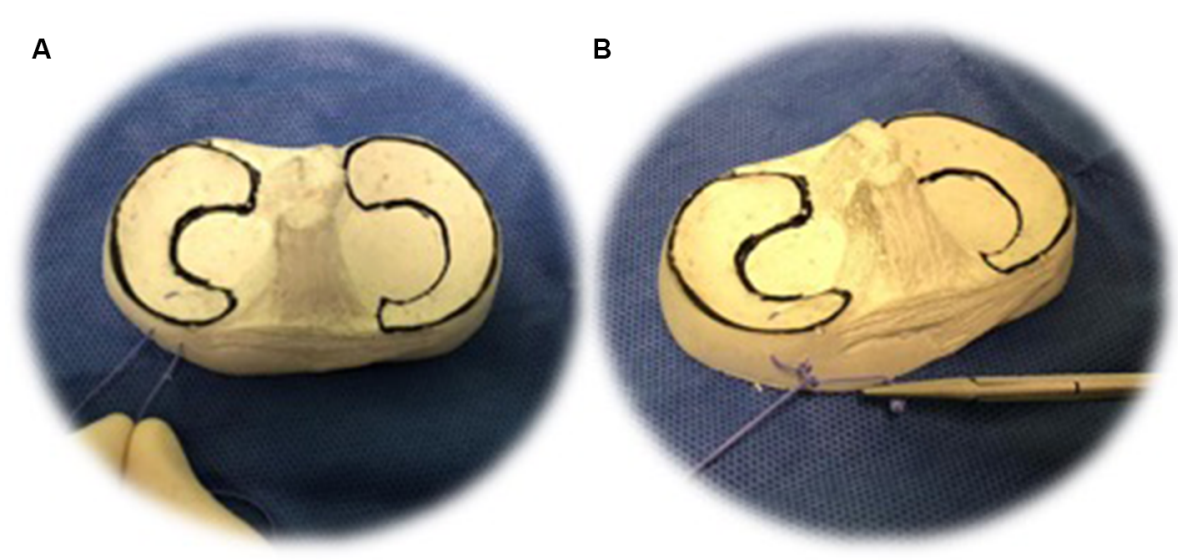

Figure $\mathbf{5}$ The surgeon pulls the wire corresponding to the loop with the hand, externalizing it $(\mathbf{A})$. It is then it is possible to test the stability and tighten the knot outside the joint capsule (B).

stitch and then tighten the knot to the joint capsule (Figure 5). Depending on the relative orientation of both needles, we will have a simple suture that can be horizontal or vertical.

\section{Discussion and conclusion}

The described outside-in suture method is technically simple, fast, and inexpensive. It allows one to perform vertical and/or horizontal sutures and does not require a big surgical incision. Other techniques using needles or other devices of larger caliber are technically more complex and require several suture and needle passages. We believe that this technique is easier and more reproducible than others previously described in the literature, requiring only few steps and low-cost material that is readily available in most operating rooms. It should also 
be noted that this technique does not require specific training and is intuitive for surgeons with arthroscopic practice. We advocate the use of an Ethibond ${ }^{\circledR}$ (Ethicon) wire and vertical sutures, whenever possible, owing to the strong biomechanical advantages that both offer in meniscal repair. ${ }^{5,6}$

\section{Disclosure}

The authors report no conflicts of interest in this work.

\section{References}

1. Keyhani S, Abbasian MR, Siatiri N, Sarvi A, Kivi MM, Esmailiejah AA. Arthroscopic meniscal repair: "Modified Outside-In Technique." Arch Bone Jt Surg. 2015;3(2):104-108.
2. Abdelkafy A, Aigner N, Zada M, Elghoul Y, Abdelsadek H, Landsiedl F. Two to nineteen years follow-up of arthroscopic meniscal repair using the outside-in technique: a retrospective study. Arch Orthop Trauma Surg. 2007;127(4):245-252.

3. O'Donnell JB, Ruland CM, Ruland LJ 3rd. A modified outside-in meniscal repair technique. Arthroscopy. 1993;9(4):472-474.

4. Laupattarakasem W, Sumanont S, Kesprayura S, Kasemkijwattana C. Arthroscopic outside-in meniscal repair through a needle hole. Arthroscopy. 2004;20(6):654-657.

5. Borden P, Nyland J, Caborn DN, Pienkowski D. Biomechanical comparison of the Fast-Fix meniscal repair suture system with vertical mattress sutures and meniscus arrows. Am J Sports Med. 2003;31(3):374-378.

6. Dervin GF, Downing KJ, Keene GC, McBride DG. Failure strengths of suture versus biodegradable arrow for meniscal repair: an in vitro study. Arthroscopy. 1997;13(3):296-300.
Open Access Journal of Sports Medicine

\section{Publish your work in this journal}

The Open Access Journal of Sports Medicine is an international, peer-reviewed, open access journal publishing original research, reports, reviews and commentaries on all areas of sports medicine. The journal is included on PubMed. The manuscript management system is completely online and includes a very quick and fair
Dovepress

peer-review system. Visit http://www.dovepress.com/testimonials.php to read real quotes from published authors. 